\title{
Gas Chromatography - Mass Spectrometry Analysis and Antibacterial Activity of Bluish-Green Pigment from Pseudomonas sp. JJTBVK (KF836502)
}

\author{
Bala Verma ${ }^{1}$, Pradeep Kumar ${ }^{1}$, Loganathan karthik ${ }^{2}$, Dharumadurai Dhanasekaran ${ }^{3}$, \\ Olubukola Oluranti Babalola ${ }^{4}$ and Shivakumar Pulakeshappa Banakar ${ }^{1,4^{*}}$ \\ ${ }^{I}$ Department of Biosciences; Shri JJT University; Jhunjhunu, Rajasthan - India. ${ }^{2}$ School of Life Sciences and \\ Biotechnology; Shanghai Jiao Tong University; Shanghai - China. ${ }^{3}$ Department of Microbiology; Bharathidasan \\ University; Tiruchirapalli, Tamilnadu - India. ${ }^{4}$ Department of Biological Sciences; Faculty of Agriculture, Science \\ and Technology; North-West University; Mmabatho - South Africa
}

\begin{abstract}
The present study was conducted for the isolation of potential bacteria from the desert soil, their molecular identification and prediction of restriction sites of the potential isolate using the bioinformatics tools. Production of the metabolites was done by inoculating in nutrient broth of pH 8.6. Metabolite was bluish-green in color; it was extracted and dried by using methanol and used for partial characterization by using GC-MS spectroscopy. Antibacterial activity was performed with the clinical human pathogenic isolates. The bacterium was identified as Pseudomonas sp. JJTBVK on the basis of $16 S$ rRNA sequencing. The sequence was analyzed for the restriction cleavage sites, which showed that the sequence had various restriction sites for different enzymes. Antibacterial activity (MIC) of methanol extract of the bacterial culture broth showed antibacterial activity (MIC), which was 29, 30, 30 and $29 \mathrm{~mm}$ for Pseudomonas aeruginosa, Staphylococcus aureus, Bacillus subtilis and Salmonella typhi, respectively. GC-MS analysis of the methanol extract showed the presence of naphth [2,3-B] azet-2 (1H) -one, 1phenyl-, which was the characteristic compound showing the antibacterial activity.
\end{abstract}

Key words: Characterisation, Pseudomonas, Extracellular, Pigment, Antibacterial activity

\section{INTRODUCTION}

Microorganisms can withstand the adverse conditions and grow in the environment by secreting various colored components as metabolites. Some microorganisms can also be identified on the basis of the type and nature of the secretion of the metabolic compounds. Pseudomonas is a Gram negative bacterium, present in the soil, water, human skin flora and also opportunistic plant pathogen. The synthesis of bluish-green, yellow-green, fluorescent, water- soluble extracellular pigments is a characteristic property of some Pseudomonas spp. under certain growth conditions. These species are members of the same intra-generic genetic homology group, e.g., Pseudomonas aeruginosa, $P$. putida, $P$. fluorescens and phytopathogens of the $P$. syringae type (Stanier et al. 1966; Palleroni et al. 1973; Palleroni and Doudoroff 1974; Meyer 1978). Pseudomonas is known to produce pigments resolved to survive under oxidative stress imposed by exhibiting antagonism, environmental variation and deposition of hazardous materials by human

*Author for correspondence: banakarsp@gmail.com 
activities. This type of beneficial bacteria form colonies on the plant surfaces and secrete potential antibiotics and hydrogen cyanide that are lethal to plant pathogens; it also promotes plant growth by suppressing the pathogens in the root zone and upper parts and by involving in nutrient assimilation. It also can be even used to control environmental hazards in the biodegradation and bioremediation, and can be used to control the phytopathogens (Jayaswal et al. 1990). Water soluble and diffusible pigments producing ability of the Pseudomonas species are the primary characteristic, which have been used for their identification. There are reports on the production of specific bluish-green colored pigment in the culture medium of $P$. aerugenosa, which consisted of blue pyocyanin and also the production of unspecific yellow colored pigment, namely fluorescin (Howarth and Dedman 1964). Pseudomonas aeruginosa produced various phenazine pigments identified as pyocyanine, phenazine-1-carboxylic acid, 1-hydroxy phenazine and phenazine-1-carboxamide (Mavrodi et al. 2001). Defined conditions for the reliable production of phenazines have greatly aided by biosynthetic studies (MacDonald 1967).

Phenazines $(\mathrm{Phz})$ are $\mathrm{N}$-containing heterocyclic pigments synthesized by Brevibacterium, Burkholderia, Pseudomonas and Streptomyces. Currently, over 50 naturally occurring Phz compounds have been described and mixtures of as many as ten different $\mathrm{Phz}$ derivatives can occur simultaneously in one organism. The growth conditions determine the number and type of $\mathrm{Phz}$ synthesized by an individual bacterial strain (Dwivedi and Johri 2003). Production of the pigments from the bacteria have been studied by inducing the stress condition by varying the media components or by the incubation conditions such as $\mathrm{pH}$ and temperature or by varying the type or composition of carbon and nitrogen sources in the medium for the higher productivity (Goswami and Bhowal 2014).

There are several health risks associated with methicillin-resistant Staphylococcus aureus (MRSA) infections, including its potential to produce invasive infections, particularly in vulnerable patients and its resistance to multiple antibiotics (Cardozo et al. 2013). Phenazines are redox-active small molecules produced by the bacteria and have been studied extensively for their roles as toxins. However, how the phenazines benefits the producing organisms is still not clear. These phenazines represent a large class of natural antibiotics that are produced by diverse bacteria and exhibit unique redox properties and broad-spectrum antibiotic activity (Marvodi et al. 2006). Pseudomonas can survive under anoxic conditions in the presence of glucose and oxidized phenazines, including pyocyanin, 1Hydroxyphenazine and phenazine-1-carboxylic acid. Many microorganisms produce phenazines, brightly colored, heterocyclic small molecules that reversibly gain and lose electrons. Pseudomonas are perhaps the best studied phenazine producers, known as agents of human infection and for their potential as biological control agents that protect agricultural crops (Marvodi et al. 2013).

The green technology comprises to produce less toxic products from natural materials for today's production lines. Some synthetic dye manufacturing has been prohibited due to the carcinogenicity of the precursor or product and also due to the issue of the administration of their industrial wastes in the ecosystem (Venil et al. 2013). Phenazine compounds are biologically active metabolites that function in microbial competitiveness (Mazzola et al. 1992). These bacterial pigments can also be used as food colorants instead of the synthetic dyes, which are not degradable easily with the nature. Natural pigments are easily degradable in the nature; they possess antimicrobial and anticancer activity, contain pro-vitamin $\mathrm{A}$ and have some desirable properties such as stability to light, heat and $\mathrm{pH}$ (Mekhael and Yousif 2009; Muthuselvam et al. 2009). Various microbial pigments such as carotenoids, prodigiosin, astaxanthin and violacein have found application in medical areas due to their activities as immunosuppressive, anticancer, anti-aging and antioxidative agents (PerezThomas et al. 2003; Williamson et al. 2007; Raj et al. 2009; Goswami and Bhowal 2014).

Pyocyanin has a variety of pharmacological effects on eukaryotic and prokaryotic cells (Vukomanovic et al. 1997) and also antibiotic activity against bacteria, fungi and protozoa (Karpagam et al. 2013). The majority of antimicrobial agents are of microbial origin. The resistance of the pathogenic microbes to the commonly used antibiotics is increasing as a result of the wide-spread and long-term use of these common antibiotics. Therefore, development of a strategy to produce effective antibiotics is an urgent need. Interspecies interactions can be the possible utility in the search of effective 
antibiotics. When different microbial species interact and communicate, as it happens in the nature, this may lead to novel pharmaceutical compounds. The aim of the present study was to search for bacterial metabolite having multiple functions such as natural color and which also acts as antimicrobial compound, which could be applied in the food and textile or under-garment industries.

\section{MATERIAL AND METHODS}

\section{Sample collection}

The soil sample was collected from the desert soils of Jhunjhunu, Rajasthan, India during September 2013 at a depth of 10-25 cm using sterile spatula and stored in a sterile polyethylene bag.

\section{Isolation and Identification of Bacteria}

The soil sample was serially diluted and the dilutions were inoculated on the nutrient agar. One of the isolates showed the bluish-green colored pigment, which was selected and sub-cultured for the cultural, morphological, biochemical and physiological characteristics identification (Cappuccino and Sherman 1999; Schaad et al. 2001); the results were compared with Bergey's Manual of Determinative Bacteriology (Buchanan et al. 1974) and further confirmed based on molecular identification.

\section{Molecular characterization}

The DNA was isolated by a commercial kit (Amnion Pvt. Ltd, India). The universal bacterial primers (Forward:- 5' - CWG RCC TAN CAC ATG SAA GTC - 3'; Reverse:- 5' - GRC GGW GTG TAC NAG GC - 3') were used for the amplification of 16S rRNA gene. The PCR was carried out in a $50 \mu \mathrm{L}$. PCR mixtures included gDNA ( $\sim 50$ ng), Forward Primer (100 ng), Reverse Primer (100 ng), $10 \mathrm{mM}$ dNTPs mix (2 $\mu \mathrm{L}), 10 \mathrm{X}$ AMTaq Pol. Buffer $(5 \mu \mathrm{L})$ and AMTaq Polymerase enzyme ( $3 \mathrm{U})$. Cycling conditions were as follows: initial denaturation at $94^{\circ} \mathrm{C}$ for 5 min, 35 cycles of $94^{\circ} \mathrm{C}$ for $30 \mathrm{~s}, 55^{\circ} \mathrm{C}$ for $30 \mathrm{~s}$, and $72^{\circ} \mathrm{C}$ for $1.30 \mathrm{~min}$, and a final extension of $5 \mathrm{~min}$ at $72^{\circ} \mathrm{C}$. The $16 \mathrm{~S}$ rRNA sequence was determined using an ABI3730XL capillary DNA sequencer (ABI Prism 310 Genetic Analyzer, Tokyo, Japan). The homology of the 16S rRNA partial gene sequence was analyzed using BLAST search (National Center for Biotechnology Information
(NCBI), USA). The phylogenetic tree was constructed by using tree view software (version 1.6.6). The restriction sites in $16 \mathrm{~S}$ rRNA gene sequence of the potential isolate was predicted using Bioinformatics tool, NEB cutter (Version 2.0).

\section{Production of Pigment}

The culture was inoculated into nutrient broth $(\mathrm{pH}$ 8.6) in the conical flask and incubated at $37^{\circ} \mathrm{C}$ for 48-72 h. The bacterial cells were separated from the liquid medium by using a refrigerated centrifuge at $12,074 \mathrm{~g}$ for $10-15 \mathrm{~min}$. The bluishgreen colored supernatant was used to extract the metabolic compounds through the methanol extraction method. Further centrifugation and filtration (Whatmann filter paper) was done to remove the insoluble components and precipitated proteins in the medium. Concentration of the pigment was done by using Buchi Roto evaporator and then it was used for further processing.

\section{Gas chromatography-mass spectrometry analysis \\ The methanol extract of Pseudomonas sp JJTBVK} was analyzed by gas chromatography-mass spectrometry (GC-MS) using a THERMO GC TRACE ULTRA VER: 5.0, Thermo MS DSQ II with a TR 5 - MS Capillary Standard Non - Polar Column (30 m, film $0.25 \mu \mathrm{m}$, ID $0.25 \mathrm{~mm}$ ). The temperature was 80 to $250^{\circ} \mathrm{C}$ at $8^{\circ} \mathrm{C} / \mathrm{min}$. The carrier gas was Helium with a flow rate of 1.0 $\mathrm{mL} / \mathrm{min}$. The chemical constituent was identified using NIST08.LIB library spectra provided by the software on a GC / MS system.

\section{Antibacterial Activity}

The methanol extract of Pseudomonas sp JJTBVK was used in different concentrations $(25,50,75$ and $100 \mathrm{mg} / \mathrm{mL}$ ) in comparison with the standard drug to study the in vitro antibacterial activity of human pathogenic bacteria to find out the minimum inhibitory concentration by agar well diffusion method. The human pathogenic clinical isolates were Staphylococcus aureus, Escherichia coli, Salmonella typhi, P. aerugenosa, Klebsiella pneumoniae, Proteus vulgaris and Bacillus subtilis. A loopful of each pathogenic bacterial culture was inoculated into the different test tubes containing $5.0 \mathrm{~mL}$ sterile Luria Bertani (LB) broth and incubated at $37^{\circ} \mathrm{C}$ for $18 \mathrm{~h}$. Then transferred $100 \mu \mathrm{L}$ of the inoculums of the each test pathogen on to different nutrient agar plates 
and spread plate method was done with a sterile swab. A well of $5.0 \mathrm{~mm}$ diameter was made in the plates equidistantly, using a sterile cork borer. Filter sterilized $(0.25 \mu \mathrm{m}$ pore size $)$ methanol extract of Pseudomonas sp JJTBVK with four different concentrations $(25,50,100$ and 200 $\mathrm{mg} / \mathrm{mL}$ ) compared with chloromphenicol (25 $\mathrm{mg} / \mathrm{mL}$ ) were tested. A $50 \mu \mathrm{L}$ of each concentration of methanol extract and standard antibiotic was transferred into their respective labeled wells and the plates were incubated at $37^{\circ} \mathrm{C}$ for $24 \mathrm{~h}$; sterile water was used as a control. Each bacterial strain was tested against the methanol extract with three replications were made during the study. After the incubation, the inhibition zone (minimal inhibitory concentration) around the well was recorded and expressed in millimeter (mm).

\section{RESULTS}

The isolated bacterium was used for the cultural and morphological study. The bacterial colony was circular, raised and smooth margin. It was a
Gram negative bacterium, rod in shape, motile and aerobic, which gave positive test for citrate utilization, starch hydrolysis, $\mathrm{H}_{2} \mathrm{~S}$ production, lipid hydrolysis, gelatine liquefaction, oxidase and catalase test and negative for methyl red, vogues procure and indole production. Based on these, the organism was identified as Pseudomonas sp. Then further confirmation was made by using molecular characterization.

\section{Molecular characterization}

On the basis of 16S rRNA partial gene sequence, the bacterium was identified as Pseudomonas sp. through the analysis of the sequence using BLAST search. It was designated as Pseudomonas sp. JJTBVK. The constructed phylogenetic tree showed the phylogenic relationship with the $P$. aeruginosa with $99 \%$ similarity (Fig. 1). The accession, given to the bacterial sequence is KF836502. The gene sequence of Pseudomonas sp JJTBVK was analyzed for restriction enzyme cleavage sites, which showed the different cleaving sites for different restriction enzymes (Fig. 2).

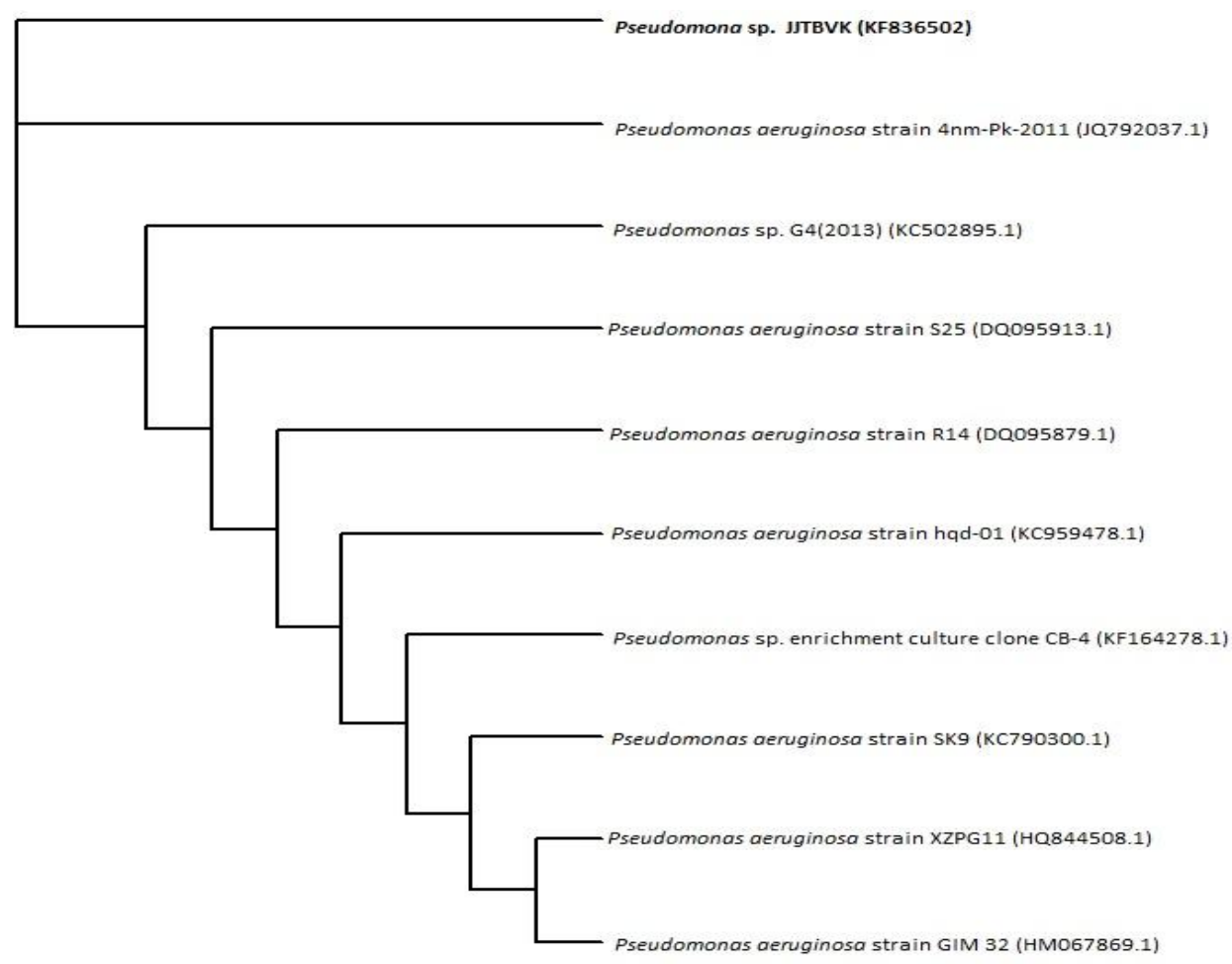

Figure 1 - Dendrogram of 16S rRNA gene sequence in Pseudomonas sp. JJTBVK. 


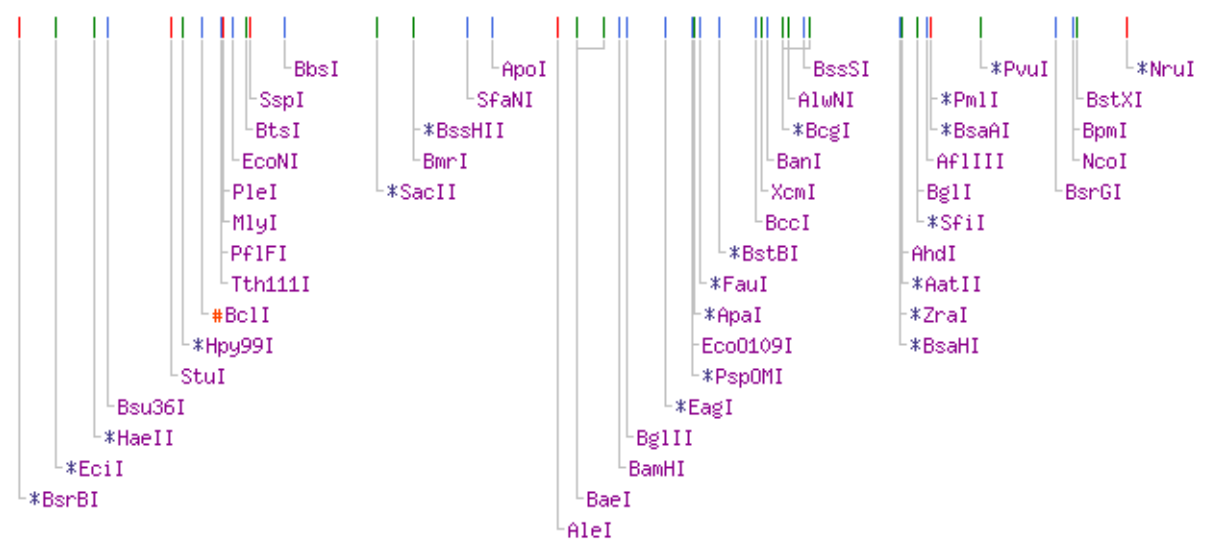

Figure 2 - Restriction enzyme cleaving sites in 16S rRNA gene sequence of Pseudomonas sp. JJTBVK.

\section{Extraction of bacterial pigment}

After the incubation, the broth was centrifuged to separate the supernatant and the metabolite was extracted using methanol, which was green in color.

Gas chromatography-mass spectrometry analysis GC-MS Chromatogram of the methanolic extracted pigment showed different peaks (Fig. 3); the highest peak was observed and identified as Naphth [2,3-B] Azet-2 (1H) -One, 1-Phenyl- (Fig. 4). The IUPAC name of this compound is 1Phenyl naphtho [2,3-b] azet-2 $(1 \mathrm{H})$-one and the

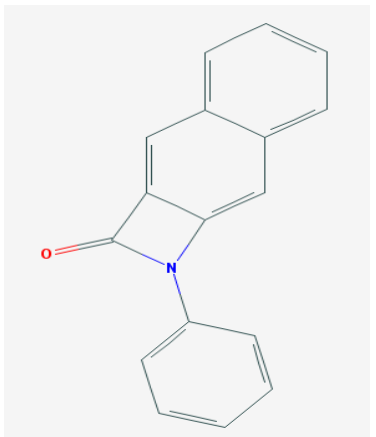

Figure 4 - Structure of Naphth [2,3-B] Azet-2 (1H) -One, 1-Phenylchemical formula is $\mathrm{C}_{17} \mathrm{H}_{11} \mathrm{NO}$.

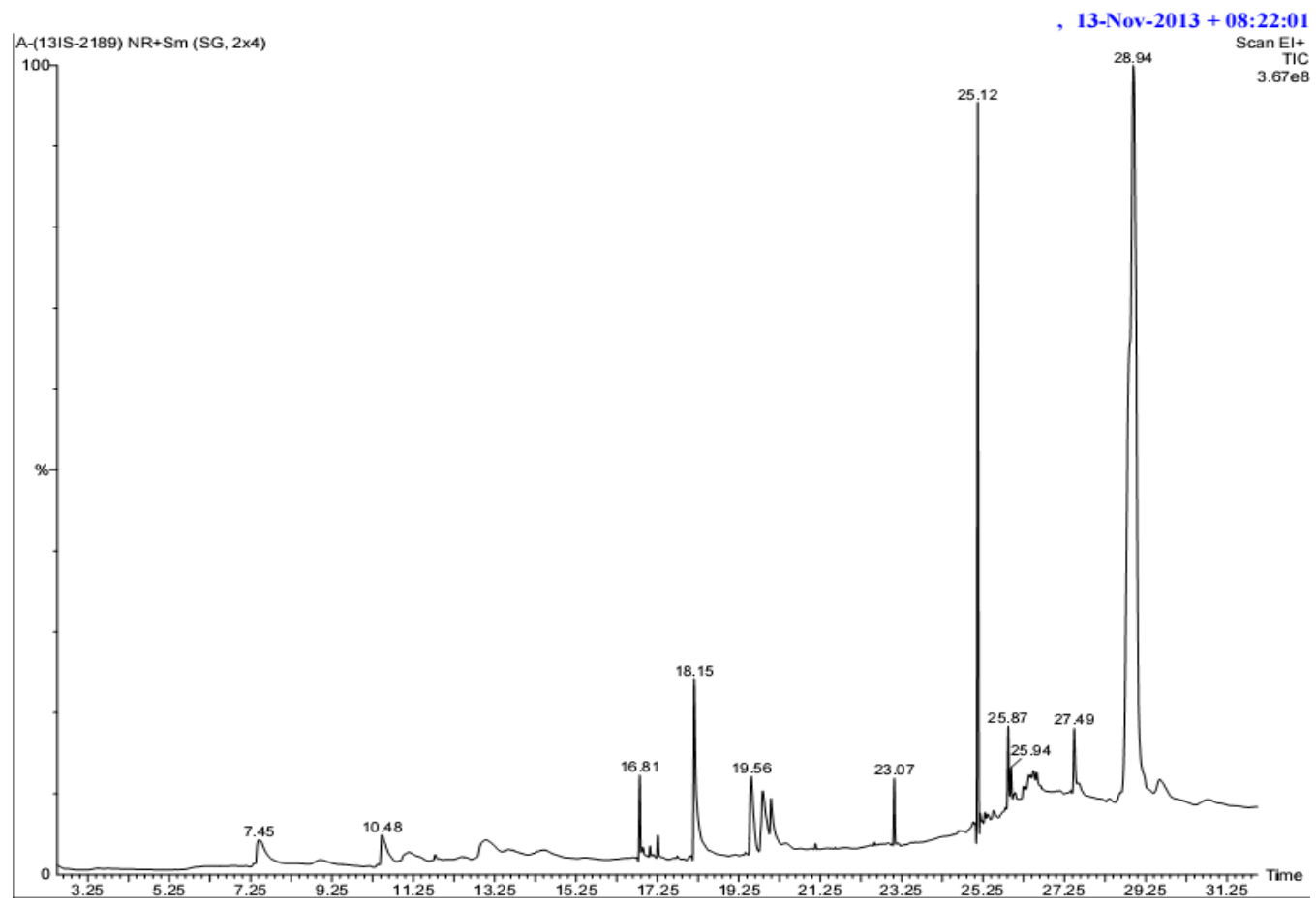

Figure 3 - GC-MS Chromatogram shows the different peaks for the extracted compound. 
Antibacterial Activity

Antibacterial activity of the methanolic extract of Pseudomonas sp. KF836502 showed significant differences in their activities depending on the microorganisms tested (Table 1). The metabolite showed the maximum zone of inhibition against $P$. aerugenosa $(32 \mathrm{~mm})$, followed by $S$. aureus $(30$ $\mathrm{mm})$, B. subtilis $(30 \mathrm{~mm})$ and Salmonella typhi (29 $\mathrm{mm})$ than other clinical isolates when compared with the standard antibiotic chloromphenicol (Fig. $5)$.

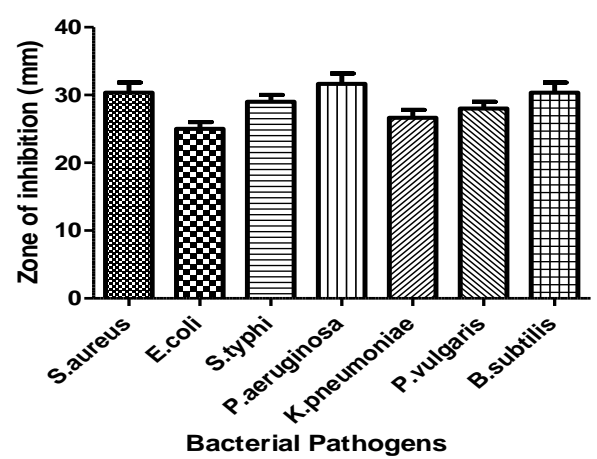

Figure 5 - Antibacterial activity of the methanol extract of Pseudomonas sp. JJTBVK.

Table 1 - Antibacterial activity of the methanol extract of Pseudomonas sp. JJTBVK.

\begin{tabular}{|c|c|c|c|c|c|}
\hline \multirow[b]{2}{*}{ Species } & \multicolumn{4}{|c|}{ Methanolic Extract (Crude) } & \multirow{2}{*}{$\begin{array}{c}\text { Standard } \\
\text { (Chloromphenicol) } \\
\end{array}$} \\
\hline & $25 \mathrm{mg} / \mathrm{mL}$ & $50 \mathrm{mg} / \mathrm{mL}$ & $75 \mathrm{mg} / \mathrm{mL}$ & $100 \mathrm{mg} / \mathrm{mL}$ & \\
\hline Staphylococcus aureus & $7 \pm 1$ & $12 \pm 2$ & $20 \pm 1$ & $30 \pm 1.5$ & $29 \pm 1$ \\
\hline Escherichia coli & $6 \pm 0.6$ & $8 \pm 1$ & $16 \pm 2$ & $25 \pm 1$ & $26 \pm 0.5$ \\
\hline Salmonella typhi & $7 \pm 1$ & $10 \pm 1.5$ & $18 \pm 2.5$ & $29 \pm 1$ & $27 \pm 1.5$ \\
\hline Pseudomonas aeruginosa & $9 \pm 1.5$ & $14 \pm 2.5$ & $22 \pm 1.5$ & $32 \pm 1.5$ & $29 \pm 2$ \\
\hline Klebsiella pneumoniae & $6 \pm 0.6$ & $9 \pm 1.5$ & $15 \pm 1$ & $27 \pm 1.2$ & $28 \pm 1$ \\
\hline Pseudomonas vulgaris & $8 \pm 2$ & $9 \pm 1.2$ & $16 \pm 2$ & $28 \pm 1$ & $28 \pm 0.5$ \\
\hline Bacillus subtilis & $9 \pm 1.5$ & $13 \pm 1.5$ & $20 \pm 1$ & $30 \pm 1$ & $29 \pm 1$ \\
\hline
\end{tabular}

\section{DISCUSSION}

Several bacterial cultures were isolated from the agricultural soil and screened for characteristic extracellular pigment producing ability. One of these was characterized as Pseudomonas sp. JJTBVK (KF836502), which produced bluishgreen colored pigment by inducing the stress condition in the media by varying the $\mathrm{pH}$. There are reports on inducing the stress by varying other conditions such as carbon source for characteristic and good rate of pigment productivity (Muthuselvam et al. 2009). An important factor is the concentration of the iron, which must be controlled to ensure the secretion of fluorescent pigments by Pseudomonas (Totter and Moseley 1953). Muthuselvam et al. (2009) reported maximum pigment productivity was at $40^{\circ} \mathrm{C}, \mathrm{pH}$ 7.0 , lactose as a carbon source and ammonium chloride as nitrogen source by the $P$. aeruginosa.

Luti and Yonis (2013) worked on the interactions with elicitor cells such as dead and live, elicited $P$. aeruginosa to produce more phenazine albeit at different levels and reported increased in the production of phenazine in elicited cultures. Based on the type of microbial elicitors such as E. coli, Bacillus subtilis and S. cerevisiae, the maximum production of phenazine was achieved in the culture elicited with heat killed cells of $S$. cerevisiae.

Naphth [2,3-B] Azet-2 (1H) -one, 1-Phenyl has beta lactum ring in its structure and belongs to the phenazine derivatives, which is responsible for antibacterial activity. The functional groups are largely responsible for differences in the physical and chemical properties of the individual phenazines, and hence their biological activity (Marvodi et al. 2006). The phenazine compounds are phenolic in nature, which include pyocyanin and pyorubrin pigments and exhibit a broad spectrum antibiotic property for both fungi and bacteria (Smirnov and Kiprianova 1990). The antagonistic effects of almost all of phenazine derivatives are usually attributed to one general characteristic redox activity (Price-Whelan et al. 2006), and these compounds have been recognized as a major factor in controlling many pathogens (Saha et al. 2008). More than 6000 phenazinecontaining compounds that have been described over the past century and around 100 are of natural origin (Smirnov and Kiprianova 1990; Laursen and Neilsan 2004).

Natural phenazines are produced almost exclusively by eubacteria; they often are excreted 
to very high levels in milligrams to grams per litre during in vitro bacterial growth and they typically are pigmented with absorption spectra that include two distinct maxima in the UV range and at least one in the visible range that varies according to the nature and position of substituents on the heterocyclic ring (Britton 1983). Some of the fluorescent Pseudomonads found in the rhizosphere region of the soil may act as plant growth promoting rhizobacteria and suppress the soil borne plant pathogenic fungi by secreting the antifungal metabolites such as pyoluteorin, pyrrolnitrin, phenazines and 2,4-di acetyl phloroglucinol (Dwivedi and Johri 2003). Luti and Yonis (2013) carried out the agar diffusion test for the antimicrobial activities of the phenazine on the elicitor microorganisms; they observed that phenazine was noticeably effective against $S$. cerevisiae and in a lesser extent against $B$. subtilis and E. coli. Some microbial pigments are sensitive to heat, light, acidity, air and water activity and unstable and highly degradable (Joshi et al. 2003); hence, this isolated phenazine compound needs to be studied for the applicability.

\section{CONCLUSION}

In the present study the molecular characterization and cleavage sites for the restriction enzymes were studied for Pseudomonas sp. JJTBVK. The culture produced Naphth [2,3-B] Azet-2 (1H) -One, 1Phenyl in alkaline $\mathrm{pH}$ conditions (under the stress conditions). These compounds have potential to inhibit the growth of the human pathogenic bacteria and used as a coloring agent in food and textile industries.

\section{ACKNOWLEDGEMENT}

The authors are thankful to JJT University, Rajasthan and North-West University, South Africa for the support.

\section{REFERENCES}

Britton G. Biochemistry of natural pigments. Cambridge, UK: Cambridge Univ. Press. 1983. Pp366.
Buchanan RE, Gibbons NE, Cowan ST, Holt TG, Liston J, Murry RG, et al. Bergey's Manual of Determinative Bacteriology. Williams and Wilkins Co., 1974. Baltimore.

Cappuccino JC, Sherman N. Microbiology, A Laboratory Manual. 1999. An Imprint of Addition Wesley Longman, Inc.

Cardozo V, Olivera AG, Nishio EK, Perugini MRE, Andrade CGTJ. Antibacterial activity of extracellular compounds produced by Pseudomonas strain against methicillin-resistant Staphylococcus aureus (MRSA) Strains. Ann Clin Microbiol Antimicrob. 2013; 12 (12): doi: 10.1186/1476-0711-12-12.

Dwivedi D, Johri BN. Antifungal from fluorescent Pseudomonads: Biosynthesis and Regulation. Curr Sci. 2003; 85(12): 1693-1703.

Goswami B, Bhowal J. Identification and characterization of extracellular red pigment producing bacteria isolated from soil. Int J Curr Microbiol App Sci. 2014; 3(9): 169-176.

Howarth S, Dedman MD. Pigmentation Variants of Pseudomonas aeruginosa. J Bacteriol. 1964; 88: 273 278.

Jayaswal RK, Fernandez MA, Schroeder RG. Isolation and characterization of Pseudomonas strain that restricts growth of various phytopathogenic fungi. Appl Env Microbiol. 1990; 56: 1053-1058.

Joshi VK, Attari D, Bala A, Bhushan S. Microbial pigments. Indian J Biotechnol. 2003; 2(3): 362-369.

Karpagam S, Sudhakar T, Lakshmipathy M. Microbicidal response of pyocyanin produced by $P$. aeruginosa toward clinical Isolates of fungi. Int $J$ Pharm Pharm Sci.2013; 5: 870-873.

Laursen JB, Nielsen J. Phenazine natural products: biosynthesis, synthetic analogues and biological activity. Chem Rev. 2004; 104:1663-1685.

Luti KJK, Yonis RW. Elicitation of Pseudomonas aeruginosa with live and dead microbial cells enhances phenazine production. Rom Biotech Lett. 2013; 18: 7169-7178.

MacDonald JC. Pyocyanin- Antibiotics and Biosynthesis. In: Biosynthesis: Antibiotics II. Edts. Gottlieb D, Shaw PD, Springer-Verlag, New York, 1967. Pp. 52-65.

Marvodi DV, Blankenfeldt W, Thomashow LS. Phenazine compounds in fluorescent Pseudomonas spp. biosynthesis and regulation. Annu Rev Phytopathol. 2006; 44: 417-445.

Marvodi DV, Prejko JA, Marvodi OV, Kwak Y-S, Weller DM, Nlankenfeidt W, et al. Recent insights into the diversity, frequency and ecological roles of phenazines in fluorescent Pseudomonas spp. Environ Microbiol. 2013; 15(3): 675-686. 
Mavrodi DV, Bonsall RF, Delaney MS, Soule MJ, Phillips G, Thomashow SL. Functional analysis of genes for biosynthesis of pyocyanin and phenazine-1carboxamide from Pseudomonas aeruginosa PAO1. J Bacteriol. 2001; 183: 6454-6465.

Mazzola M, Cook RJ, Thomashow LS, Weller DM, Pierson III LS. Contribution of phenazine antibiotic biosynthesis to the ecological competence of Fluorescent Pseudomonas in soil habitats. Appl Environ Microbiol.1992; 8: 2616-2624.

Meyer JM. The Fluorescent Pigment of Pseudomonas fluorescens: Biosynthesis, Purification and Physicochemical Properties. J Gen Microbiol.1978; 107: 319-328.

Muthuselvam M, Sheeba T, Rajasekaran R. Analysis of Microbial Pigment Productivity in Pseudomonas aeruginosa and Bacillus subtilis. J Advanced Biotech. 2009; 10-14.

Palleroni NJ, Doudoroff M. The genus Pseudomonas. In Bergey's Manual of Determinative Bacteriology, 8th edn, Edited by Buchanan RE, Gibbons NE. Williams and Wilkins. Baltimore. 1974. Pp. 217-243.

Palleroni NJ, Kunisawa R, Contopoulou R, Doudoroff M. Nucleic acid homologies in the Genus Pseudomonas. Int J Syst Bacteriol.1973; 23: 333-339.

Perez-Tomas R, Montaner B, Llagostera E, SotoCerrato V. The Prodigiosis, Proapoptotic Drugs with Anticancer Properties. Biochem Pharmacol. 2003; 66: 1447-1452.

Price-Whelan A, Dietrich LEP, Newman DK. Rethinking 'secondary' metabolism: physiological roles for phenazine antibiotics. Nat Chem Biol. 2006; 2: 71-78.

Raj DN, Dhanasekaran D, Thajuddin N, Panneerselvam A. Production of Prodigiosin from Serratia marcescens and its Cytotoxicity Activity. J Pharma Res. 2009; 2: 590-593.
Saha S, Thavasi R, Jayalakshmi S. Phenazine pigments from Pseudomonas aeruginosa and their application as antibacterial agent and food colorants. Res $J$ Microbiol.2008; 3: 122-128.

Schaad NW, Jones JB, Chun W. Laboratory Guide for Identification of Plant Pathogenic Bacteria. APS Press St. Paul M N. 2001.

Smirnov VV, Kiprianova EA. Bacteria of Pseudomonas genus. NaukovaDumka, Kiev, Ukraine, 1990, pp. 100-111.

Stanier RY, Palleroni NJ, Doudoroff M. The aerobic Pseudomonads: A taxonomic study. J Gen Microbiol.1966; 43: 159- 271.

Totter JR, Moseley FT. Influence of the concentration of iron on the production of fluorescin by Pseudomonas aeruginosa. J Bacteriol.1953; 65: 4547.

Venil CK, Zakaria ZA, Ahmad WA. Bacterial pigments and their applications. Process Biochem. 2013; 48: 1065-1079.

Vukomanovic DV, Zoutman DE, Stone JA, Marks GS, Brien JF, Nakatsu K. Electrospray massspectrometric, spectrophotometric and electrochemical methods do not provide evidence for the binding of nitric oxide by pyocyanin at $\mathrm{pH} 7$. Biochem J. 1997; 322: 25-29.

Williamson NR, Fineran PC, Cristwood SR, Chawral SR, Leeper FJ, Salmond GPC. Anticancer and Immunosuppressive properties of bacterial prodigionines. Future Microbial. 2007; 2: 605-618.

Received: March 16, 2015; Accepted: May 03, 2015. 